\title{
Água e saúde: bens públicos da humanidade
} JOSÉ DA ROCHA CARVALHEIRO ${ }^{I}$

\section{Desenvolvimento sustentável}

$\Lambda$ IDEIA de desenvolvimento sustentável é associada à reunião realizada no Rio de Janeiro em 1992, a "Cúpula da Terra”, ou Eco-92, ou ainda Rio

92. Nela foi aprovado o compromisso denominado Agenda 21 que considera "desenvolvimento sustentável" o modo de progresso do mundo (global) em que melhorem (com equidade) as condições de vida da atual geração, sem prejuízo das gerações vindouras. Embora seja muito mais ampla, essa ideia é com muita frequência associada a questões ambientais que incluem o aquecimento global associado à emissão de gases resultantes da degradação de combustíveis fósseis. Numa perspectiva mais abrangente, associa-se com os Objetivos do Milênio e contempla três eixos: ambiental, econômico e social. Numa óbvia intersecção entre eles, hábitos contemporâneos são responsabilizados pela degradação do ambiente urbano simbolizado na falta de saneamento básico: contaminação do ar, da água e do solo por dejetos humanos e resíduos industriais. Há uma tendência recente de estender esse compromisso a outros setores influenciados fortemente pelo comportamento dos indivíduos que compõem a população: mobilidade urbana, por exemplo. Um debate que ganha força na atualidade é a questão da predominância do mercado transformando em mercadoria o que já foi tido como "bens públicos". Voltaremos a esse tema.

Tendo sido presidente da Rio 92, Gro Harlem Brundtland, médica e política socialista, primeira ministra da Noruega, teve seu nome associado à ideia de desenvolvimento sustentável. Por essa razão foi incluída na lista dos (200) maiores economistas da Enciclopedia y Biblioteca Virtual de las Ciencias Sociales, Económicas y Jurídicas (Brundtland, 2015). Juntou-se a nomes ilustres como Adam Smith, Karl Marx, Schumpeter, Keynes e outros. A lista tem hoje mais de mil nomes.

\section{Dia Mundial da Água}

Na Rio 92 é proposto um Dia Mundial da Água, sempre em 22 de março. O lema e a(s) entidade(s) multipolar(es) responsáveis variam anualmente, mas sempre se promovem atividades e produz-se um Relatório. Algumas atividades propostas para o público são notáveis pelo inusitado: por exemplo, "não usar as torneiras da casa durante todo o dia” (no relatório de 1993).

O lema de 2015, de responsabilidade do PNUD, foi “Água e desenvolvi- 
mento sustentável", uma oportunidade importante de consolidar as ênfases dadas nos "Dias da Água” dos anos anteriores. Nesses, água foi associada a energia, segurança alimentar, desafios urbanos, limpeza e mundo saudável, saneamento, desastres (eventos extremos), mulheres, escassez hídrica, entre outros.

Em 2015 o PNUD deu ênfase a um aspecto específico da água fresca: "Water Supply and Sanitation”. Deu maior importância a estatísticas assombrosas (ver original inglês no Anexo 1):

Globalmente, quase 1 bilhão de pessoas não têm água potável; 2,4 bilhões de pessoas não têm acesso a saneamento; 1,2 bilhão carece de quaisquer instalações e serviços de saneamento. A cada dia, 5.000 crianças em média morrem devido a doenças relacionadas com água e saneamento, muitas facilmente evitáveis (PNUD, 2015).

Em 2000, através dos Objetivos de Desenvolvimento do Milênio (ODM), a comunidade internacional comprometeu-se a reduzir, até 2015, pela metade a proporção de pessoas sem acesso a água potável e saneamento básico. No geral, o mundo está a caminho de cumprir o ODM da água, mas há grandes lacunas em muitas regiões e países, particularmente na África Subsaariana. Com as tendências atuais, o mundo não atingirá a meta de saneamento por um débito de 1 bilhão de pessoas.

Atingir as metas de água e saneamento dos ODM é mais do que uma questão de saúde e dignidade. Há evidência convincente de que alcançar as metas de água e saneamento promoveria um grande salto adiante no desenvolvimento humano:

Desenvolvimento Humano está mais ligado ao acesso à água e ao saneamento do que outros motores de desenvolvimento que o PNUD examinou, incluindo gastos com a saúde e/ou educação e o acesso a serviços de energia.

A crise da água e do saneamento afeta esmagadoramente os pobres. A disponibilidade de água é certamente uma preocupação para alguns países. Mas a crise global de água e saneamento é principalmente enraizado na pobreza, no poder e na desigualdade, não na disponibilidade física. É, antes de tudo, uma crise de governança e reforma, assim, a reforma da governança deve ser um pilar fundamental de qualquer abordagem estratégica para enfrentar a crise.

Surpreende a maneira e os exemplos que o PNUD apresenta para justificar que "Água é saúde" (ver original inglês no Anexo 2):

Água é saúde: Lavar as mãos pode salvar sua vida;

A água é natureza: Ecossistemas estão no cerne do ciclo global da água;

A água é urbanização: Toda semana, um milhão de pessoas se mudam para as cidades;

A água é indústria: Mais água é usada para a fabricação de um carro do que para preencher uma piscina;

A água é energia: Água e energia são amigos inseparáveis;

A água é alimento: Produzir dois bifes (bistecas) consome 15.000 litros de água;

A água é a igualdade: A cada dia as mulheres gastam milhões de horas carregando água (UNDP, 2015) 
A referência às bistecas (two steaks) faz lembrar ideia importante em análise pelos especialistas sobre a "pegada da água" (footsteps). Apesar de dar ênfase às condições de pobreza, o relatório assinala, como desigualdade, apenas a de gênero.

\section{Água e desenvolvimento}

Não foi apenas o PNUD, neste ano de 2015, responsável pela celebração do Dia Mundial da Água, que deu ênfase à relação com o desenvolvimento. Em documento recente, de uma série dedicada a "Desenvolvimento Sustentável e Saúde", a representação em Brasília da Organização Pan-Americana da Saúde (Opas, 2014) já encaminhava o debate para elaborar indicadores que pudessem identificar desigualdades (no Brasil).

Recupera documento anterior à Rio 92, produzido pela ONU (1987) e chamado "Brundtland Report", que identifica a necessidade de mensurar os avanços no desenvolvimento sustentável em três dimensões: social, ambiental e econômica. O documento da Opas (2014) emprega engenhosa proposta metodológica que se inicia pela inclusão da saúde na interseção dessas três dimensões, baseada no documento final da Reunião Rio+20 (2012): "saúde é uma condição prévia, um resultado e um indicador das três dimensões do desenvolvimento sustentável". Associa esses quatro campos a Objetivos Do Milênio (ODM) e escolhe um indicador (I) para traduzir cada um deles:

Dimensão social: ODM (universalizar a educação primária); I (taxa de analfabetismo)

Dimensão econômica: ODM (erradicar a extrema pobreza e a fome); I (proporção de pobres)

Dimensão ambiental: ODM (garantir a sustentabilidade ambiental); I (taxa de cobertura de água encanada)

Saúde (interseção): ODM (reduzir a mortalidade na infância): I (taxa de mortalidade infantil)

A partir dessas escolhas, apresenta as tendências desses indicadores no Brasil, de 1991 a 2010, por meio de engenhoso diagrama triangular que alberga os valores em relação ao ideal, traduzidos pelos quartis Q1 e Q3. A distância interquartil dá uma ideia da desigualdade.

Considerando a maneira como os autores escolheram os indicadores, fica reforçada a ideia da estreita e relevante associação da saúde com o acesso à água encanada como alicerces do desenvolvimento sustentável.

\section{Os rumos globais}

\section{Propriedade privada no século XXI}

Analisar os rumos do capitalismo, ou da "hegemonia do mercado", neste século XXI remete ao que se entende por esquerda e direita na atualidade. O polêmico filósofo Peter Singer (2000) considera que a esquerda "necessita de novo paradigma, em vista do colapso do comunismo (real) e do abandono pelos 
socialistas democráticos da ideia de eliminar a propriedade privada dos meios de produção". Há considerável volume de críticas à sua proposta de uma esquerda que admita que é inevitável o caminho da humanidade para uma cordial cooperação. Haveria a seleção natural dos mais solidários, uma espécie de "darwinismo social".

Importante contribuição recente sobre as tendências do fim do século XX nos apresenta uma visão muito menos otimista (Judt, 2014). Referindo-se à realidade dos Estados Unidos, por comparação aos Estados europeus de "bem-estar social", defende que essa construção histórica está associada a circunstâncias que dificilmente se repetirão. Em particular identifica "grupos de interesse" e sua atuação desenfreada que os transforma de cidadãos em consumidores. A essa ideia de dualidade cidadão-consumidor assinala que as ciências sociais americanas a denominam hiphenization. Essa sociedade, repleta de grupos "com hífen", não é novidade. Há décadas, foi identificada pelo geógrafo brasileiro Milton Santos (1987) em sua inteligente distinção entre usuário (aceita tudo sem discutir), consumidor (briga por interesse pessoal) e cidadão que "é um ser multidimensional... na procura de um sentido para a vida; o que dele faz o indivíduo em busca do futuro, a partir de uma concepção de mundo". Na área da saúde coletiva, a Epidemiologia é tratada como "ciência da saúde do ser social" pelo epistemólogo argentino Juan Samaja (2003), num texto instigante que a associa com a geografia num texto em que homenageia Milton Santos. Nada mais justo do que apontar para essa tendência de analisar os rumos do bem-estar da humanidade do que recorrer a uma epidemiologia "Miltoniana". Claro está que a "crise hídrica", objeto deste trabalho, merece uma abordagem com essa feição.

\section{Os "novos donos do mundo" e o "elogio ao predador"}

A crise do mercado, no Brasil, está claramente expressa na atuação do ministério público e do judiciário em questões de grande apelo na atualidade. São "operações" designadas por nomes que passam a pertencer ao jargão popular e acabam por encaminhar à prisão poderosos empresários e políticos, nunca antes atingidos por punições dessa natureza no Brasil.

Lamentavelmente, o mesmo passa no mundo, dito desenvolvido, a julgar por impressionante dossier "Les nouveaux maîtres du monde", publicado pelo Le Monde Diplomatique em maio de 1995. São seis artigos extremamente contundentes sobre a maneira de proceder dos grandes empreendedores, os "magnatas" ou "novos donos do mundo". Estivesse publicado em português pela imprensa brasileira no mês de junho de 2015, pensaríamos que se referisse à "Erga omnes", 14 a fase da "Operação Lava Jato".

A chamada de capa do Le Monde, "Eloge du prédateur", de autoria de Ricardo Petrella (1995), relata o diálogo entre um magnata inglês com o âncora de um conceituado programa de TV. Vamos reproduzir, em tradução livre (o original em francês está no Anexo 3): 
Em 2 de abril, o canal Arte TV dedicou uma noite à especulação financeira. O programa incluiu uma entrevista, conduzida por Anthony Sampson, com o empresário britânico James Goldsmith, que expôs seus pontos de vista de forma nua e crua sobre o assunto:

James Goldsmith - Eu acredito em mudança e que, sem mudança, chega a decadência. Pode ser uma coincidência, mas empresas como Bank of America e General Motors, todas as multinacionais norte-americanas, para não mencionar as empresas britânicas ou francesas que esclerosaram, são cada vez menos competitivas, porque não se atreveram a evoluir. Se a escolha é entre uma mudança brutal e a continuidade tranquila, a última é a solução mais desastrosa. É como dizer que é muito difícil se levantar de manhã, é melhor ficar na cama Sair para a rua é perigoso, mas não temos escolha.

Anthony Sampson - Mas, se todos tivessem um espírito empreendedor como o seu, seria impossível viver neste mundo.

James Goldsmith - Não estou de acordo, definitivamente. É como dizer que, na natureza, a vida é impossível por causa de predadores. Isso me faz pensar nas pessoas bem-intencionadas que criaram uma reserva para proteger as presas dos grandes felinos. Os animais terminam por enfraquecer e morrem, porque os predadores são um estímulo necessário. É o que acontece no mundo dos negócios se eliminamos os predadores para criar burocracias confortáveis e monopólios. Sem os predadores, a indústria morre, as empresas periclitam, o país definha e as pessoas sofrem muito mais do que se estivessem submetidas à estimulação e à concorrência.

Resta-nos, apenas, lamentar que para evitar que a indústria venha a morrer, prejudicando o desenvolvimento, os predadores sejam "um estímulo necessário".

\section{Água e saúde, direitos humanos: são bens públicos da humanidade}

Quando se pensa na água e na saúde como bens públicos da humanidade, e na ideia do desenvolvimento sustentável, o Relatório do Dia Mundial da Água de 2001 (WHO World Water Day Report, 2001), de responsabilidade da então Diretora da WHO, Gro H. Bruntland, oferece a mensagem principal em instigante prefácio associando "água, saúde e desenvolvimento" (o original em inglês está no Anexo 4):

Água para a Saúde - Tomando conta, Coordenado pela Organização Mundial de Saúde (OMS).

A mensagem para o Dia da Água: esforços concretos são necessários para fornecer água potável e melhorar a saúde, bem como aumentar em todo o mundo a conscientização dos problemas e das soluções; 22 de março é uma ocasião única para lembrar a todos que as soluções são possíveis; ajude a transformar palavras em ação e compromisso político. 
Abastecimento de água potável e saneamento adequado para proteger a saúde estão entre os direitos humanos básicos. Garantindo a sua disponibilidade contribuiria imensamente para a saúde e produtividade para o desenvolvimento. "Business as usual" não é mais uma opção. Nós não temos tempo suficiente para esperar por grandes investimentos em infraestrutura para fornecer serviços básicos a todos os que deles necessitam. Várias intervenções simples estão disponíveis, tais como a melhoria da qualidade da água na casa, bem como melhorar a educação de higiene a nível familiar. As pessoas pobres podem tomar conta de seus próprios destinos e melhorar suas vidas através da aplicação de algumas destas medidas. Mas eles precisam saber o que funciona e como tais intervenções podem ser exploradas.

Destacamos dois pontos essenciais sobre a disponibilidade de água (limpa): (1) é indispensável para a saúde e a produtividade, bases do desenvolvimento; (2) não é uma opção ser tratada como um "negócio qualquer". Essa é a mais evidente contradição atual entre direitos e mercadorias, ou cidadãos e consumidores, já mencionados acima (Judt, 2014; Santos, 1987). De resto, Tony Judt menciona como exemplo: hoje, quando pedimos um copo de água num bar, nos perguntam “com gás ou sem gás”?

A hiphenization é traduzida, na atual "crise hídrica" que nos assola, pelo surgimento de intensa propaganda de empresas de perfuração de poços artesianos. Há um óbvio interesse de setores industriais e agrícolas que têm na água um insumo essencial ao processo produtivo. Mas faz sucesso também em comunidades fechadas (condomínios habitacionais) que se mobilizam para encontrar solução privada para o abastecimento. Água, direito coletivo, passa a ser tratada como mercadoria. Não espanta saber que a maioria dos municípios já terceirizou o abastecimento para empresas que abrem seu capital em bolsas de valores, no Brasil e no exterior. Os especialistas consideram digno de análise o processo em curso na vizinha Bolívia, onde consta a existência de um processo de "desprivatização" das companhias de abastecimento de água (Hailu et al., 2009).

A alternativa aos grupos de interesse (consumidores) poderia ser uma ação política voltada para a garantia de direitos da cidadania. As "manifestações de rua", convocadas pelas redes sociais raramente produzem efeitos concretos perceptíveis. Mas, podem ser substituídas por manifestações programadas por agremiações formalmente constituídas. Em São Paulo, foi o caso de ato público, chamado por um Coletivo Luta pela Água (Figura 1). O noticiário assinala: "Cansados da falta de transparência da Sabesp, manifestantes reivindicam comitê de crise com participação popular para planejar o enfrentamento da seca" (Gomes, 2015). Um comitê de crise aponta para uma realidade da política atual: é preciso garantir a governança com a inclusão de todas as correntes relevantes e que essas correntes prestem contas a seus segmentos (accountability). Já mencionamos a questão da governança ao analisar o relatório do PNUD (2015).

Esse Coletivo Luta pela Água está associado à Fundação Perseu Abramo, instituída pelo Partido dos Trabalhadores em 1996. Isso nos permite uma re- 
flexão derradeira. Diante das visões otimista (Peter Singer) ou pessimista (Tony Judt) a respeito do século XXI: o que representam organismos (fundações, coletivos e similares) ligados a partidos políticos?

A meu juízo, são o caminho necessário para conduzir o processo com o sentido de transformar consumidores em cidadãos, conforme preconizado por Milton Santos.

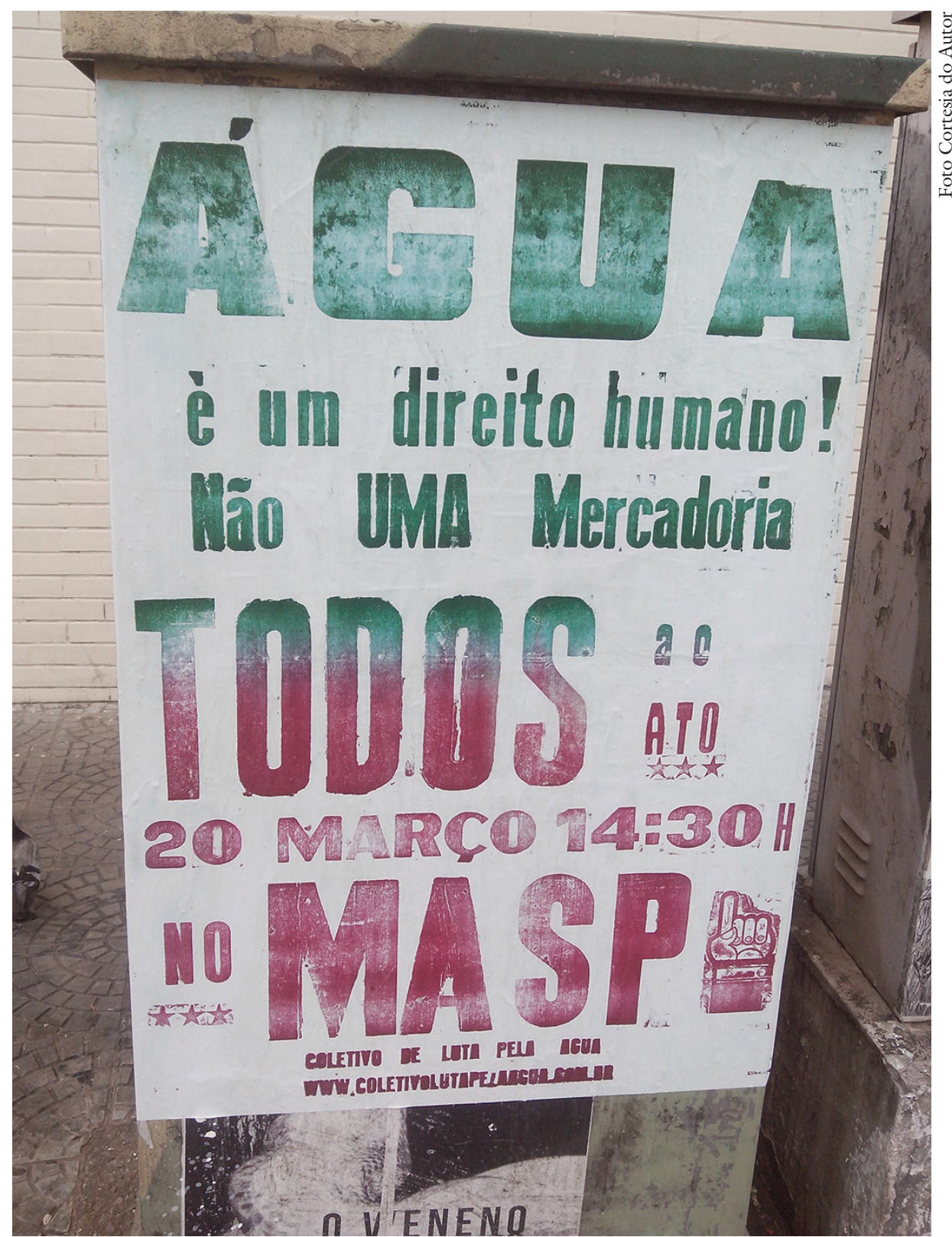

Figura 1 - Propaganda num bloco de cimento ao lado da Estação Vila Mariana do Metrô. 
Referências

BRUNDTLAND, G. H. Enciclopedia y Biblioteca Virtual de las Ciencias Sociales, Económicas y Jurídicas. eumed.net - Enciclopedia virtual, 2015. Disponível em: <http:// www.eumed.net/cursecon/economistas/gro_harlem_brundtland.htm $>$. Acesso em: 24 jun. 2015.

GOMES, R. Manifestantes pedem fim do racionamento seletivo de água e plano de contingência. Fundação Perseu Abramo, 21.3.2015. Disponível em: <http://novo.fpabramo.org.br/content/manifestantes-pedem-fim-do-racionamento-seletivo-de-agua-e-plano-de-contingencia>. Acesso em: 24 jun. 2015.

HAILU, D.; OSORIO, R.; TSUKADA, R. Privatização e reestatização da água na Bolívia: estão os pobres em melhor situação? Centro Internacional de Políticas para o Crescimento Inclusivo; Grupo de Pobreza, Escritório de Políticas para o Desenvolvimento do PNUD; One pager, n.100, out. 2009. Disponível em: <http://www.ipc-undp.org/ pub/port/IPCOnePager100.pdf>. Acesso em: 20 jun. 2015.

JUDT, T. Pensando o século XX. Rio de Janeiro: Objetiva, 2014.

ONU - Report of the World Comission on Environment and Development: Our Common Future. Brundtland Report, 1987.

OPAS - Desenvolvimento sustentável e Saude: tendências dos indicadores e desigualdades no Brasil. Brasília, DF: Opas, 2014.

PETRELLA, R. Eloge du prédateur. Les nouveaux maîtres du monde. Le Monde Diplomatique, mai 1995.

SAMAJA, J. Desafios a la epidemiologia (pasos para una epidemiologia "Miltoniana"). Rev. Bras. Epidemiol., v.6, n.2, p.105-20, 2003.

SANTOS, M. O espaço do cidadão. São Paulo: Nobel, 1987.

SINGER, P. Una izquierda darwiniana: política, evolución y cooperación. Barcelona: Editorial Crítica, 2000.

UNDP. Water Supply and Sanitation. World Water Day, 2015. Disponível em: <www. undp.org/.../water-supply-and-sanitation.html>. Acesso em: 20 jun. 2015.

WHO. World Water Day Report. Geneva: WHO, 2001. Disponível em: <http://www. who.int/water_sanitation_health/takingcharge.html>. Acesso em: 24 jun. 2015.

RESUMO - O desenvolvimento sustentável foi mais divulgado após a Rio-92. Nesse encontro foi criado o Dia Mundial da Água, celebrado anualmente. Em 2001, pela OMS, tivemos “Água para Saúde”, que afirma que ambos são "bens públicos da humanidade". Em 2015, pelo PNUD, “Água e Desenvolvimento Sustentável” mostra que é uma constante associar água, saúde e desenvolvimento e comparar suas propostas aos Objetivos de Desenvolvimento do Milênio (ODM). Consideramos que os rumos globais, na atualidade, colocam em debate a propriedade privada no século XXI.

PALAVRAS-CHAVE: Água e saúde bens públicos, Desenvolvimento sustentável, Dia Mundial da Água, Objetivos de Desenvolvimento do Milênio (ODM).

ABSTRACT - Sustainable development was more widespread after Rio-92. This meeting was created World Water Day, celebrated annually. In 2001, the WHO had "Water for 
Health" which states that both are "public goods of humanity". In 2015, UNDP, "Water and Sustainable Development" shows that it is a constant associate water, health and development and compare their proposals to the Millennium Development Goals (MDGs). We believe that the actual global debate puts in question the private property in the XXI century.

KEYWORDS: Water and health public goods, Sustainable development, World Water Day, Millennium Development Goals (MDG).

José da Rocha Carvalheiro é médico e professor titular de Medicina Social da Faculdade de Medicina de Ribeirão Preto da USP. Foi colaborador-pleno do Instituto de Estudos Avançados da USP. @-jrcarval@fiocruz.br

Recebido em 25.6.2015 e aceito em 13.7.2015.

I Faculdade de Medicina de Ribeirão Preto, Universidade de São Paulo. São Paulo/SP, Brasil. 


\section{Anexo 1}

Globally, almost 1 billion people lack clean drinking water. 2.4 billion people have no access to bygienic sanitation facilities; 1.2 billion lack any sanitation facilities at all. Each day, an average of 5,000 children die due to water and sanitation related diseases, many easily preventable (UNDP, 2015).

In 2000, through the Millenium Development Goals (MDGs), the international community committed to halving the proportion of people without access to clean water and basic sanitation by 2015. Overall, the world is on track to meet the water MDG, but there are major gaps in many regions and countries, particularly in Sub-Saharan Africa. On current trends, the world will miss the sanitation target by a staggering 1 billion people.

Meeting the MDG water and sanitation targets is more than a bealth and dignity issue. The evidence is compelling that achieving the water and sanitation goals would trigger a major leap forward in human development:

Human Development is more closely linked to access to water and sanitation than other development drivers UNDP has examined, including spending on bealth or education, and access to energy services.

The crisis in water and sanitation overwhelmingly affects the poor. Availability of water is certainly a concern for some countries. But the global water and sanitation crisis is mainly rooted in poverty, power and inequality, not in physical availability. It is, first and foremost, a crisis of governance and thus governance reform must be a key pillar of any strategic approach to addressing the crisis.

\section{Anexo 2}

Water is health: Clean hands can save your life;

Water is nature: Ecosystems lie at the heart of the global water cycle;

Water is urbanization: Every week, one million people move into cities;

Water is industry: More water is used to manufacture a car than to fill a swimming pool;

Water is energy: Water and energy are inseparable friends;

Water is food: To produce two steaks (bistecas) you need 15.000 liters of water;

Water is equality: Every day women spend millions of hours carrying water (UNDP, 2015)

\section{Anexo 3}

Le 2 avril, la chaîne de télévision franco-allemande Arte a consacré une soirée à la spéculation financière. Figurait notamment au programme un entretien, mené par Anthony Sampson, avec l'homme d'affaires britannique James Goldsmith, qui, en 1989, a exposé sans fard ses vues sur la question:

James Goldsmith - Je crois au changement et je crois que, sans changement, on arrive à la décadence. C'est peut-être une coüncidence, mais des sociétés comme 
la Bank of America ou General Motors, toutes les multinationales américaines, sans parler des anglaises ou des entreprises françaises qui se sont sclérosées, sont de moins en moins compétitives parce qu'elles n'ont pas osé évoluer. S'il faut choisir entre un changement brutal et la continuité tranquille, il apparaît en dernier ressort que cette dernière est la solution la plus désastreuse. C'est comme si on disait qu'il est trop pénible de se lever le matin et qu'il vaut mieux rester au lit. Sortir dans la rue, c'est déjà dangereux, mais on n'a pas le choix.

Anthony Sampson-Mais si tout le monde avait un esprit d'entreprise comme le vôtre, il serait impossible de viove dans ce monde.

James Goldsmith - Je ne suis pas d'accord du tout. C'est comme si vous disiez que, dans la nature, la vie est impossible à cause des prédateurs. Ça me fait penser à ces gens bien intentionnés qui avaient créé une réserve pour protéger le gibier des grands fauves. Les animaux ont fini par dépérir et par mourir parce que les prédateurs constituent un stimulant nécessaire. C'est ce qui arriverait dans les affaires si on éliminait les prédateurs pour créer de confortables bureaucraties et des monopoles. Sans les prédateurs, l'industrie mourrait, les entreprises péricliteraient, le pays dépérirait et les gens souffriraient bien davantage qu'en étant soumis à la stimulation et à la concurrence.

Anexo 4

Water for Health-Taking Charge

Coordinated by the World Health Organization (WHO). The message for the day was: "Concrete efforts are necessary to provide clean drinking water and improve health as well as to increase awareness world-wide of the problems and of the solutions. 22 March is a unique occasion to remind everybody that solutions are possible. Use the resources on this site to help turn words into political commitment and action.

Safe water supply and adequate sanitation to protect health are among the basic human rights. Ensuring their availability would contribute immeasurably to health and productivity for development. "Business as usual" is no longer an option. We don't have enough time to just wait for large infrastructure investments to provide these basic services to all who need them. Several simple interventions are available, such as improving the quality of water in the home as well as improving bygiene education at the household level. Poor people can take charge of their own destinies and improve their lives by applying some of these measures. But they need to know what works and how such interventions can be exploited. 
